\title{
Current role of heparin in thromboprophylaxis of major orthopaedic surgery
}

\author{
Biławicz J ${ }^{1}$, Trzebicki $J^{1}$ and Kostrubiec $M^{2 *}$ \\ ${ }^{1}$ Department of Anaesthesiology and Intensive Care, The Medical University of Warsaw, Poland \\ ${ }^{2}$ Department of Internal Medicine and Cardiology, The Medical University of Warsaw, Poland
}

\section{Introduction}

Total knee replacement (TKR), total hip replacement (THR), and hip fracture (HFx) surgeries carry a high risk for venous thromboembolism (VTE), which includes deep vein thrombosis (DVT) and pulmonary embolism (PE) [1]; it is estimated that about 5 percent of patients undergoing the above major orthopaedic surgery could have symptomatic VTE without prophylaxis. However, thromboprophylaxis and increasing use of early mobilization have caused the recent decrease in the postoperative VTE rate. The antithrombotic prophylaxis reduces the incidence of deep vein thrombosis (DVT) by $50 \%$ to $60 \%$ and pulmonary embolism (PE) by about two-thirds [2]. For patients undergoing THR or TKR the recommendation is to use one of the following for a minimum of 10 to 14 days: low-molecular-weight heparins (LMWHs), fondaparinux, apixaban, dabigatran, rivaroxaban, low-dose unfractionated heparin, adjusted-dose vitamin $\mathrm{K}$ antagonist (VKA), aspirin, or an intermittent pneumatic compression device[1]. Despite the increasing popularity of direct oral anticoagulants (DOACS), the LMWH are still the main option for in-hospital prophylaxis.

\section{Pharmacodynamics and pharmacokinetics of LMWHs}

About 95\% of unfractionated heparin (UHF) components exhibit both anti-Xa and IIa actions. On the other hand, the LMWHs contain less than $30 \%$ of molecular components showing both anti-Xa and anti-IIa actions. Only high-molecular-weight molecules are able to potentiate the inhibition of anti-IIa, whereas inhibition of factor Xa is not dependent on molecular weight [3]. The relative prevalence of oligosaccharides presenting sole anti-Xa activity is much higher than in UHF. Moreover, the clearance of heparin components is different than with the LMWHs, and over time the anti-Xa/IIa ratio of LMWHs increases [4]. It was suggested in animal studies that a high of anti$\mathrm{Xa}$ to anti-IIa activity may be related to a reduced tendency to cause bleeding [5]; however, it has not yet been confirmed in clinical trial. Importantly, despite different production LMWH technologies influencing the chemical structure of glucosamine chains and their functional groups, their anti-Xa activity and inhibition of haemostatic system activation is very similar [6].

Heparin leads to the release of tissue factor pathway inhibitor (TFPI), which has inhibitory effects on the coagulation cascade [5]. Increases in the concentration of free TFPI are similar after single doses of UHF or LMWH [7], but effects may differ after multiple doses. After five days of administration of UHF, total TFPI activity is partially depleted, but not following injection of LMWH [8].

Heparins interact also with platelets. Platelet factor 4 (PF4), which is released by activated platelets, has a strong potential to inhibit high- molecular-weight fractions of heparin [9]. Importantly, it has a much weaker effect on the low-molecular-weight fractions that inhibit factor $\mathrm{Xa}$ activity. Therefore the anti-Xa activity of LMWHs is largely intact in the face of PF4 inhibition [10]. However, the anti-IIa action of LMWH is reduced by PF4, and overall antithrombotic activity is retained [10] In contrast, UHF can be completely inactivated in the presence of PF4 [10]. UHF can both inhibit platelet aggregation [11], and cause platelet activation [12]. However, the effect of LMWHs on platelets is less extreme, as both the activation and the inhibition of platelets is weaker than that of UHF [11].

UHF binds to endothelial cells with much higher affinity than LMWH, that may be partly responsible for the faster degradation and elimination of UHF, and explain the poor bioavailability of UHF after subcutaneous administration compared with LMWH [3]. LMWHs are easily absorbed from subcutaneous tissue and have a lower tendency to bind to endothelial cells. The bioavailability of anti-Xa activity varies from about $87 \%$ for dalteparin, about $91 \%$ for enoxaparin, up to $98 \%$ for nadroparin [13].

Heparins are partially degraded by the liver to inactive fragments and are partially eliminated by the kidneys ${ }^{3}$. In a comparative study between enoxaparin 20mg and 40mg, dalteparin 2500IU, and nadroparin 7500IU injected subcutaneously, the average apparent total body clearance of enoxaparin was $15.6 \mathrm{~mL} / \mathrm{min}$. This was considerably lower than that of dalteparin $(33 \mathrm{~mL} / \mathrm{min})$ and nadroparin $(21.4 \mathrm{~mL} /$ $\min$ ) [13]. Consequently, dalteparin is cleared from the body more rapidly than nadroparin and enoxaparin. Importantly, for enoxaparin $20 \mathrm{mg}$ and $40 \mathrm{mg}$, urinary excretion represents $6.4 \%$ and $8.7 \%$ of the injected dose, which differs from those of nadroparin $(3.9 \%)$ and dalteparin (3.4\%) [13]. Enoxaparin has a longer apparent half-life (mean 4.1 hours) in the anti-Xa assay than dalteparin (mean 2.8 hours) and nadroparin (mean 3.7 hours), which is a reflection of their respective clearance values [13]. LMWHs' anti-Xa clearance decreases with the degree of renal function [4]. Therefore, dosage reduction is recommended in patients with severe renal impairment (creatinine clearance $<30 \mathrm{~mL} / \mathrm{min}$ ).

Correspondence to: Kostrubiec M, Department of Internal Medicine \& Cardiology, The Medical University of Warsaw, Poland, E-mail: maciej. kostrubiec@wum.edu.pl

Received: March 02, 2018; Accepted: March 22, 2018; Published: March 25 2018 


\section{Clinical efficiency and safety}

The retrospective, observational, cross-sectional, cohort analysis of 113,936 patients after a major orthopaedic surgery revealed a similar rate of venous thromboembolism in the group receiving thromboprophylaxis with dalteparin $(2.1 \%)$ and with enoxaparin $(2.3 \%)$ as prevalence of major bleeding ( $1.1 \%$ vs. $1.5 \%$, respectively) [14].

Anderson et al. compared aspirin to LMWH in a randomized multi-center study that recruited 778 patients. After 28 days, there was no difference in efficacy ( 1.3 vs. $0.3 \%, \mathrm{p}=0.22)$ or bleeding complication ( 5.8 vs. $3.6 \%$; $=0.45$ ) between the cohorts [15]. The meta-analysis of three randomized clinical trials that compared apixaban to LMWH following TKA $(n=7,337)$ noted that DVT rates were lower in the apixaban group $(\mathrm{p}=0.007)$ but there was no difference in the risk for $\mathrm{PE}$ $(\mathrm{p}=0.06)$ [16]. Moreover, the study found less major bleeding within the apixaban cohort $(\mathrm{p}=0.034)$. A further meta-analysis $(\mathrm{n}=24,385$ patients) demonstrated that two different oral factor Xa inhibitors (FXaI) (apixaban and rivaroxaban) were superior to $\mathrm{LMWH}$ in preventing DVT after THA and TKA (OR 0.44, 95\%CI: 0.31-0.63; $\mathrm{p}<0.00001)$ [17].

Meta-analysis of thromboprophylaxis intervention after major orthopaedic surgeries of 127 randomized clinical trials and 15 nonrandomized clinical trials [18] showed for THR that LMWH has lower risk than UHF of various VTE outcomes and major bleeding. In addition, it was indicated that LMWHs and aspirin have similar risks of total PE, symptomatic DVT, and major bleeding. Moreover, in the THR group LMWH causes less major bleeding than direct thrombin inhibitors (DTI), but DTI has lower DVT risks. Apparently, thromboprophylaxis with LMWH was associated with a lesser rate of major bleeding than with vitamin $\mathrm{K}$ antagonists (VKA). By and large, LMWH and FXaI comparisons are inconsistent across VTE outcomes, but it seems that LMWH cause less major bleeding. Interestingly, longer duration LMWH had lower risk of various VTE outcome risks, while higher dose LMWH lowered total DVT risk with increase of major bleeding.

In the TKR group [18], LMWH thromboprophylaxis showed lower DVT risks than VKA, but VKA had less major bleeding. On the other hand, FXaI appeared to have lower risk than LMWH of various VTE outcomes, while LMWH caused less major bleeding but more studydefined serious adverse events. In the group undergoing TKR higher dose DTI has lower DVT risk, but leaded to a higher rate of major bleeding. Similarly, higher dose FXaI also decreased the risk of various VTE outcomes. In contrast, LMWH had a lower rate of total DVT than FXaI for HFx surgery.

\section{Conclusion}

LMWHs were considered the gold standard for the prevention of VTE in major orthopaedic surgery for many years, although they have not shown themselves to be superior to any of the other chemoprophylactic agents. LMWHs remain widely used in tromboprophylaxis after major orthopaedic surgeries, despite growing usage of direct thrombin inhibitors and factor Xa inhibitor, which may have superior efficacy, but their safety profile still must be studied further.

\section{References}

1. Falck-Ytter Y, Francis CW, Johanson NA, Curley C, Dahl OE, et al. (2012) Prevention of VTE in orthopedic surgery patients: Antithrombotic Therapy and Prevention of Thrombosis, 9th ed: American College of Chest Physicians Evidence-Based Clinical Practice Guidelines. Chest 141: e278S-e325S. [Crossref]

2. Hill J, Treasure T, Guideline Development Group (2010) Reducing the risk of venous thromboembolism (deep vein thrombosis and pulmonary embolism) in patients admitted to hospital: summary of the NICE guideline. Heart 96:879-882. [Crossref]

3. Hirsh J, Warkentin TE, Shaughnessy SG, Anand SS, Halperin JL, et al. (2001) Heparin and low-molecular-weight heparin: mechanisms of action, pharmacokinetics, dosing, monitoring, efficacy, and safety. Chest 119:64S-94S. [Crossref]

4. Fareed J, Hoppensteadt D, Walenga J, Iqbal O, Ma Q, et al. (2003) Pharmacodynamic and pharmacokinetic properties of enoxaparin: implications for clinical practice. Clin Pharmacokinet 42:1043-57. [Crossref]

5. Matthíasson SE, Lindblad B, Stjernquist U, Bergqvist D (1995) The haemorrhagic effect of low molecular weight heparins, dermatan sulphate and hirudin. Haemostasis 25: 203-211. [Crossref]

6. Wolzt M, Eder M, Weltermann A, Entlicher J, Eichler HG, et al. (1997) Comparison of the effects of different low molecular weight heparins on the hemostatic system activation in vivo in man. Thromb Haemost 78:876-879. [Crossref]

7. Bara L, Bloch MF, Zitoun D, Samama M, Collignon F, et al. (1993) Comparative effects of enoxaparin and unfractionated heparin in healthy volunteers on prothrombin consumption in whole blood during coagulation, and release of tissue factor pathway inhibitor. Thromb Res 69: 443-452. [Crossref]

8. Hansen JB, Sandset PM, Huseby KR, Huseby NE, Bendz B, et al. (1998) Differentia effect of unfractionated heparin and low molecular weight heparin on intravascular tissue factor pathway inhibitor: evidence for a difference in antithrombotic action. $\mathrm{Br} J$ Haematol 101: 638-646. [Crossref]

9. Bendetowicz AV, Kai H, Knebel R, Caplain H, Hemker HC, et al. (1994) The effect of subcutaneous injection of unfractionated and low molecular weight heparin on thrombin generation in platelet rich plasma--a study in human volunteers. Thromb Haemost 72: 705-712. [Crossref]

10. Padilla A, Gray E, Pepper DS, Barrowcliffe TW (1992) Inhibition of thrombin generation by heparin and low molecular weight (LMW) heparins in the absence and presence of platelet factor 4 (PF4). Br J Haematol 82:406-413. [Crossref]

11. Cade JF, Buchanan MR, Boneu B, Ockelford P, Cater CJ, et al. (1984) A comparison of the antithrombotic and haemorrhagic effects of low molecular weight heparin fractions: the influence of the method of preparation. Thromb Res 35: 613-625. [Crossref]

12. Xiao Z, Theroux P (1998) Platelet activation with unfractionated heparin at therapeutic concentrations and comparisons with a low-molecular-weight heparin and with a direct thrombin inhibitor. Circulation 97: 251-256. [Crossref]

13. Collignon F, Frydman A, Caplain H, Ozoux ML, Le Roux Y, et al. (1995) Comparison of the pharmacokinetic profiles of three low molecular mass heparins--dalteparin, enoxaparin and nadroparin--administered subcutaneously in healthy volunteers (doses for prevention of thromboembolism). Thromb Haemost 73: 630-640. [Crossref]

14. Shorr AF, Sarnes MW, Peeples PJ, Stanford RH, Happe LE, et al. (2007) Comparison of cost, effectiveness, and safety of injectable anticoagulants used for thromboprophylaxis after orthopedic surgery. Am J Health Syst Pharm 64: 2349-2355. [Crossref]

15. Anderson DR, Dunbar MJ, Bohm ER, Belzile E, Kahn SR, et al. (2013) Aspirin versus low-molecular-weight heparin for extended venous thromboembolism prophylaxis after total hip arthroplasty: a randomized trial. Ann Intern Med 158:800-806. [Crossref]

16. Huang J, Cao Y, Liao C, Wu L, Gao F (2011) Apixaban versus enoxaparin in patients with total knee arthroplasty. A meta-analysis of randomised trials. Thromb Haemost 105: 245-253. [Crossref]

17. Russell RD, Huo MH (2013) Apixaban and rivaroxaban decrease deep venous thrombosis but not other complications after total hip and total knee arthroplasty. $J$ Arthroplasty 28:1477-1481. [Crossref]

18. Balk EM, Ellis AG, Di M, Adam GP, Trikalinos TA (2017) Venous Thromboembolism Prophylaxis in Major Orthopedic Surgery: Systematic Review Update. Rockville. [Crossref]

Copyright: (C2018 Biławicz J. This is an open-access article distributed under the terms of the Creative Commons Attribution License, which permits unrestricted use, distribution, and reproduction in any medium, provided the original author and source are credited. 